\title{
On Implicit Mode of Speech Reporting in Chinese Advertisements
}

\author{
Jianwu Peng \\ Foreign Languages School, Shandong University of Science and Technology, Qingdao, China \\ Email: pengpjw2000@hotmail.com
}

\begin{abstract}
The use of reported speech is a very important aspect of persuasion in advertisements. This paper is intended to analyze how implicit mode of reported speech is employed in the sale or marketing of products. It is argued that reported speeches in advertisements are shaped by the interplay of linguistic and non-linguistic knowledge, and their meaning can be best accounted for in the framework of knowledge-for-use. The analysis of Chinese advertisements has proved how useful implicit reporting is in enhancing persuasiveness in advertising.
\end{abstract}

Index Terms — reported speech, implicit mode, advertisements, persuasiveness, Chinese

\section{INTRODUCTION}

Advertising communication is a social activity which functions to facilitate the selling of products or services. Effective advertisements can draw the consumers' attention to the products, change their mind and persuade them to take the action of purchasing, no matter their actual needs. To lead consumers into buying, copywriters have to organize the advertisements into meaningful patterns for their audience. Relying primarily on personal observations, the author finds that there are some non-canonical uses of reported speech whose source is more or less muffled or implicit. The use of these reports can be a very important aspect of persuasion in the sale or marketing of a product.

\section{PREVIOUS StUdies OF REPORTED SPEECH}

The initial studies place emphasis on direct and indirect speech and the transformational relationship between them. In grammar books and language textbooks, there seems to be a general agreement that reported speech refers to a clear linguistic category which needs little definition. However, there are many other cases in which speakers or writers report language events using forms and structures which receive virtually no coverage in traditional studies. Voloshinov(1973) is right in arguing that any attempt to treat indirect speech solely in terms of mechanical transformations is bound to distort the picture. Dixon (1991) starts from verbs which signal reports and examines the structures in which they function, whether or not the structure includes a separate reported clause. Thompson (1996) says, "A lexical approach (with some formal extensions to cope with, for example quotes signaled only by inverted commas) seems more promising, since a very large number of language reports are associated with the presence of clearly identifiable lexical signals such as reporting verbs"(p.506). Leech and Short (1981) proposed a model of speech and thought presentation to cope with the analysis of real texts. As Thompson (1996) argues, this model "is comprehensive in its coverage, and, although it starts essentially from functional considerations, it sets out linguistic criteria by which the different categories can be identified" (p.504). In recent years, some scholars turned their attention to the conversational and pragmatic functions of reported speech. Tannen (1989) explores the conversational functions of reported speech in oral communication. Baynham (1996) suggests us to study reported speech in a specific discourse or context. Collins (2001) regards reported speech as a category of discourse analysis which requires reference to the larger discourse. Operating within a pragmatic framework, he examines the factors that motivated the choice of some reporting strategies at the expense of other equally possible forms. For him, the varieties of reported speech present a continuum with indeterminate boundaries between the individual types and with many instances of deliberate slippage from one form to another, a phenomenon quite common universally. Thompson (1996) argues that reported speech can "be best approached from a functional rather than structural angle, although it is desirable to draw on- as far as possible- a list of the structural and lexical features which may be used to signal the reports"(p.502). He has established a framework which is able to describe the reported speech identified in a survey of naturally-occurring texts and include the major features that emerged from these data as needing to be accounted for. By drawing on a large corpus of written English (the COBUILD Bank of English), he argues for an analytical taxonomy that is based on the speaker's decision whether or not to include another voice. Thompson regards reported speech as signalled voices in the text which include "any stretch of language where the speaker or writer signals in some way that another voice is entering the text, in however muffled or ambiguous a fashion" (Thompson, 1996, p. 506). This definition includes as wide a range of types of reported speech as possible, which can help us to capture more fully the nature of reporting phenomenon and of the choices made by users of the language in any particular context. 


\section{IMPLICIT MODE OF SPEECH REPORTING}

According to Sinclair (1988), the choice made by users of the language in any particular instance is between averral and attribution. The text is taken as averring anything which is not specifically attributed to another source. In contrast, any case of attribution can be seen as a marked option, encouraging an investigation of the reason why the speaker has chosen it. That is, it makes a difference whether a person's speech is explicitly or implicitly reported. In the case of explicit reports, reported speeches can be easily recognized because it can be attributed to the person by means of reporting signals, such as reporting verbs or quotation marks etc. However, there are other examples which clearly reporting someone else's speech but which do not fall into these categories. Thompson (1996) proposes five functional options for speech reporting according to whose voice is entering the text: self, specified other(s), unspecified other(s), community, unspecifiable other(s). However, in saying "another voice is entering the text"(p.506), Thompson seems to think that the text is there first and serves as a frame in which a stretch of language can be embedded; otherwise, there is nowhere for another voice to enter. In fact, reported speeches may involve those utterances that, as a whole, represent "another voice". That is, an utterance itself constitutes the "text" from another source rather than something which enters some other text being studied.

(1) Development is a hard Principle!

This is a banner hung in front of Foreign Languages Bookstore, Fuzhou Road, Shanghai, China. Our cognitive flexibility can help us to attribute this utterance to our late chairman Deng Xiaoping, that is, this utterance represents his voice, rather than the banner designer, who acts here as a reporter. The banner writer here does nothing but report Deng's guiding lines. Therefore, Thompson's definition of language reports needs expanding to incorporate those reports whose source is more or less ambiguous or implicit. The problem which is worth investigating here is: What knowledge resources lie behind the use of it? Which processes operate on the knowledge resources? What motivates the reporter to omit the source of the reported information? Akatsuka (1985) claims in his two-stage model of information incorporation that human information storage can be divided into two domains, one called Realis and the other called Irrealis, as shown in Figure.1:

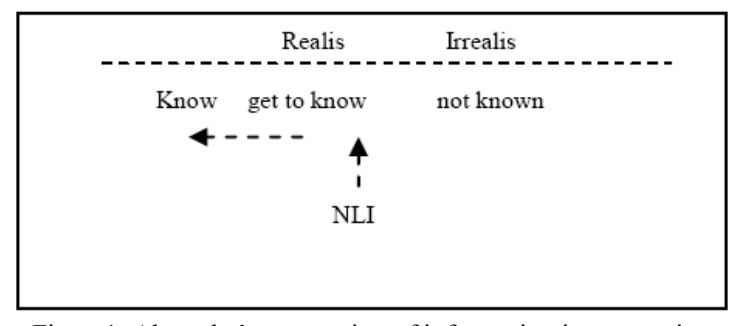

Figure1. Akatsuka's conception of information incorporation

According to Akatsuka, NLI ( Newly Learned Information) first enters the domain of Irrealis and only after a certain amount of information processing, does it move into the domain of Realis, thus becoming established as a piece of knowledge. For this example, Deng's remark must be first expressed with the source specified, like "Deng Xiaoping said, 'Development is a hard Principle!'. This usage persists until a considerable amount of information about Deng's remark has been accumulated in our mind. Only when, for example, we have already read or heard various news reports and know for sure that it is Deng who uttered this sentence, can the direct form "Development is a hard Principle!" be used. This is because through repeated activation, this information has become "entrenched" (that is, well-established and readily activated), in our mind. Obviously, in some cases, unspecified voices(s) can be identified, depending on shared knowledge rather than explicit reporting signals. Thus, if one wants to go deeply into the domain of reporting, one has to introduce socially or culturally shared knowledge beyond purely linguistic ones. In fact, there are many cases in which one really reports what other people say, but he or she intentionally omits the reportive markers for the purpose of achieving specific communicative goal.

\section{The PERSUASIVE Role OF IMPLICIT RePOrting In CHINESE AdVERTISEMENTS}

Miller (1980) defines a persuasive act as a message that is intended to shape, reinforce, or change the response of another, or others. Generally speaking, persuasiveness can be achieved by presenting reasonable arguments, examples, testimony, and so on to provide good evidence with better organization of the message. The observations of Chinese advertisements have pointed to some of the complexities inherent in the use of reported speech, and to the displays of creative agency that it frequently involves. Making decisions about when and how to use reported speeches can challenge any copywriter. When used properly, they will add strength to the persuasive force of advertisements.

\section{A. Quoting from Authorities or Celebrities}

In daily life, people often show respect and worship towards authorities or celebrities. So the copywriter can quote experts, film star, etc to evaluate and comment on the products advertised. Their opinions can attract the consumer's attention and interest and arouse their desires to take "buying" action. The authority can also be fictive, as in: 
(2) Chinese herb has quick and lasting tonifying effects on kidney. (Guangzhou Daily, 2001.12.27)

Our world knowledge (script) serves as a trigger for another voice. In this advertisement, the utterance may evoke MEDICAL CONSULTATIOM Script, which is illustrated in the Figure below:

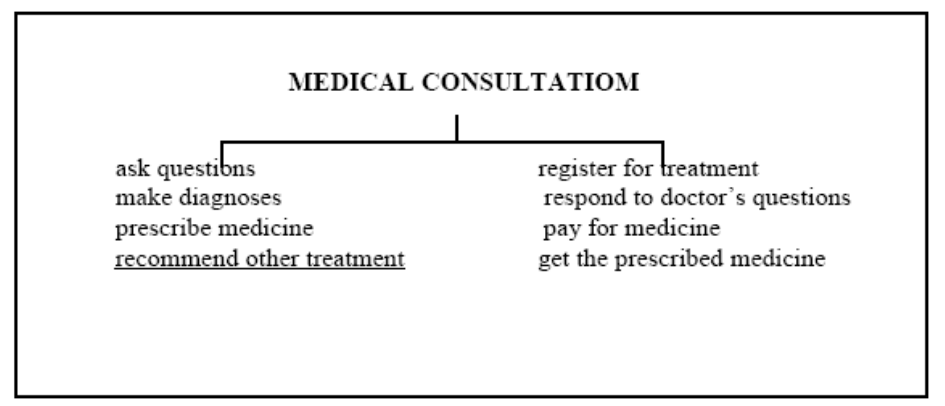

Figure 2. Medical Consultation Script

Usually it is the doctor, rather than the patient who makes recommendations or suggestions for one's recovery from illness. That is, "making suggestions" (underlined part) is one of many components inherent to the doctor's role. Thus it is very likely that the reader associates it with doctor's voice. In fact, the reported utterance of this type frequently occur in advertisements. Here the identification of doctor's voice coincides with the expectation that the doctor often give suggestions for further treatment. Usually, the reader or hearer is not a rational agent. The above sentence is deliberately created to convey a persuasive message under the doctor's mask so that the receiver gets a delusive impression that it is the doctor's suggestions for the patient, rather than copywriter who reports this news, since the script of hospital evokes such interpretation. This may be the copywriter's strategy for advertising purpose, because the attribution may bypass consumers' consciousness and lead them into believing it also voices the authority's opinion.

\section{B. Quoting from Popular Lyrics}

The copywriter can resort to other texts to persuade customers or consumers by associating the message to other cultural artifacts, although they originate outside the current text. However, since this interrelationship is not worded, copywriters must resort to very well-known texts (Fuertes-Olivera et al, 2001, p.1303). For example, popular songs appeal much to young people. Copywriters can also quote a line from these songs to get the consumer's attention.

(3) I want to have a house, which doesn't need 100,000RMB to decorate. (Morning News, 2002.10.28)

The above advertisement resembles some lines of the song "I want to have a family, which doesn't need gorgeousness" by Pan Meichen, a popular singer in Taiwan, China, only with some modifications. This deviant use of the popular lyrics can serve as a kind of "hook" to facilitate memory. In this way, this advertisement can be easily memorized and make a lasting impression on consumers. In fact, the linguistic forms departing from the conventions or rules of language have the function of attracting notice and promoting long-term purchase. In this example, the deviant use of the lyrics can serve as a kind of "hook" to facilitate memory. In this way, this advertisement can be easily memorized and make a lasting impression on consumers.

\section{Another Voice as Mouthpiece}

Tejera (1995) argues that as the addressee with whom the writer wishes to communicate is absent and even unknown, the writer has to enter into a dialogue with himself, shifting his position back and forth between the speaking subject and the assumed addressee in the process of writing. We may consider the some expressions in advertisements as reportive in nature in the sense that they represent another voice. That is, the verb of saying is unexpressed, but is implied in the construction and meaning of the sentence. For example, the manipulative purpose can lead the copywriter to identify himself with consumers who participating in the purchase, which makes it possible to bring "empathy" into play, for empathy means “the speaker's identifying himself with, in varying degrees, persons who participating in the event he describes in a sentence" (Ransom, 1997, p.424). In this way, the copywriter can induce consumers to accept him as their mouthpiece, thus preparing for "buying" act.

(4) Xinhua desirable residence. Down payment of 96000 RMB. Easy buy. Very cheap. (Shanghai Property Market Weekly. 2001.02.22)

The copywriter uses the last utterance "Very Cheap!" to represent the voice from a would-be house purchaser. The voice must remain unspecified, since each reader is in fact being implicitly encouraged to accept it as his own voice. It is irrelevant for the reader to ask whose voice is from. Here the speaker echoes purchasers' voice; however, if the voice is explicitly specified, the manipulative effect the advertiser intends to achieve will lose force. Tannen (1989: 109) points out, when a speaker represents an utterance as the words of another, what results is a constructed dialogue, which represents an active, creative, transforming move which expresses the relationship not between the quoted party and the topic of talk but rather the quoting party and the audience to whom the quotation is delivered.

\section{Nonhuman Reported Speaker}


Thompson (1994) points out that in most cases, reported speeches have humans as the speaker. However, we also find there is something non-human used as the reported speaker. In the advertisement below, the printer advertised serves as the speaker, who says:

(5) If you don't want to go to printing factory, please employ me. (Reference News, 2002.09.05)

It seems that the copywriter is identifying himself with the printer. Here the printer seems to act as a job-seeker, expecting the boss (e.g. "consumer") to accept "him" as an employee. It can be seen that the construction of a voice which is recognizably wise or foolish, serious or unserious, and so forth, depends upon the imitation of such voices as they are found in actual human affairs or as they are thought to be within various social milieux. We can say that fictive voices are modeled upon voices typically associated with the speech of persons fulfilling certain functions or occupying certain positions in a social order: e.g. persons of high or low social status. In real discourse, there are utterances which imitate the manner or the style normally used in real communication. The copywriter pretends to report, in some way or another, by imitating everyday oral conversation. In fact, various kinds of invented utterances draw their force from directly mimicking real-life communications, but also from borrowing from the rich source of other texts, with regard to its techniques as well as with regard to its "spirit". Generally speaking, all imaginary reported speech should be fitted into familiar stereotypes. It is woven of stereotypical cultural narratives, drawing on those texts that are most familiar in our culture.

\section{E. Quoting from Common People}

In advertising, the testimonial comment can be made by people, either real or fictive. The utterance in the following example may be produced by a trainee who has indeed benefited from designer training; however it may also be a fictive character, invented by the copywriter for persuasive purpose. In either of these two cases, this utterance represents another voice other than from the copywriter.

(6)After completing practical designer training course, I can process orders on my own! (Global times, 2001.12.07)

Anderson (1986) points out, "when the speaker (first person) was a knowing participant in some event, the knowledge of that event is normally direct and the sources of information are then often omitted" (p.277). In this example, the speaker "I" is a knowing participant in training, so the reporting signal such as "I say" is omitted. In some advertisements, using the testimonial words provided by the fictive or imaginary people is more appropriate and persuasive than using the real people; however, the testimonial words must conform to the identities of the people described. That is, the advertised people should be qualified to make comment, evaluation on the product or service. Only in this way can the persuasive force be achieved.

\section{F. Reports of Formulaic Language}

Formulaic language is a cover term for ready-made constructions, such as proverbs, idioms, collocations, set phrases, etc. Thompson (1996) argues, "both speaker and hearer know that these words have been used before. There is no need to specify the source" (p.509). According to Tatira (2001), proverbs and other witty sayings permeate virtually all economic activities and can be employed to promote retail businesses, industrial products, the transportation industry, preventive health practices, and many other ventures. The powerful images and succinct nature of indigenous proverbs make them especially suited for advertising. The fact that proverbs often comment on widespread human experiences enables them to remain relevant; they fit any place, time, and function in spite of the technological advancement of a particular community. They can be used to establish a familiar and authoritative context for giving advice and establishing business relationships they can be employed to invite new or continued interest in products and companies.

(7)A man of noble character acquires his wealth by honorable means. Please read Nanfang Financial Report. (Public Health Newspaper, 2002.10.23)

The formulaic expression "A man of noble character acquires his wealth by honorable means" is so entrenched in the Chinese mind that the use of it may make this advertisement noticeable, and meaningful. According to Cacciari and Glucksberg (1995), people rely on familiar, memorized phrases and expressions, and on the set of meanings and cultural values that are associated with words when the discourse context requires it. In some cases, formulaic language can also be used in deviate form, which defeats the receiver's expectations for the regular choice. The intentional choice of deviation is based on the speaker's knowledge of the expectations of a specified listener and it is motivated by communicative functions of foregrounding and/or enriching meanings of discourse. The linguistic forms departing from the conventions or rules of language have the function of attracting notice, sustaining memory, arousing interest of the consumers and thus promoting long-term purchase.

Taking into account the interplay of linguistic and non-linguistic knowledge necessary in the implicit use of reported speech, we have illustrated the persuasive role and the causes that underlie the different varieties of reported speech. We have also examined how the conditions of context reflect purposive use of speech-reporting strategies, showing how these reports contribute to the overall meaning construed by the text. It can be seen that the copywriters have available a wide range of ways in which they can choose to introduce reported speeches into their advertisements. However, the choice of specific reporting form is subject to their communicative goals. To get the consumer to do purchasing, they must determine what they will like their audience to receive, then create some texts with reported speeches they find most persuasive and effective. In fact, advertisements often have complex sets of addressers and addressees. Rather than one single voice in a text sending a message to a single group of people, there might be several voices and audience groups. 
The norms of appropriateness in an individual text must ultimately be determined by the successful deployment of such choices and combinations within the text itself.

It should go without saying that this paper offers only the barest beginning of an account of reported speeches in advertisements. To paint a complete picture of reported use of language in advertisements, we need a far larger database than was possible. With a larger database it would be possible to isolate and compare the frequency and distribution in advertisements where language events are reported, which may add to the depth of the discussion. In conclusion, in the analysis of reported speech, the cognitive, psychological, contextual (situational, social and cultural) and linguistic knowledge do combine and they are reflected through advertising discourse. A comprehensive account of reported speech needs not only to explain why people appeal to another voice in the first place, it must also be able to deal with the reasons why people should adopt one reporting strategy over another in a particular discourse context and what functions such reporting fulfils in a particular context of use.

\section{REFERENCES}

[1] Akatsuka, N. (1985). Conditionals and epistemic scale. Language 61, 625-639.

[2] Baynham, M. (1996). Direct speech: What's it doing in non-narrative discourse? Journal of Pragmatics, 25, 1, 61-81.

[3] Cacciari, C. and S. Glucksberg. (1995). Imaging idiomatic expressions: literal or figurative meanings? Journal of Experimental Psychology, 124: 3-21.

[4] Collins. D. E. (2001). Reanimated voices: speech reporting in a historical-pragmatic perspective. Pragmatics \& Beyond New Series 85. John Benjamins.

[5] Dixon, R.M.W. (1991). A New Approach to English Grammar, on Semantic Principles. Oxford: Clarendon Press.

[6] Fuertes-Olivera, P. A. et a..(2001). Persuasion and advertising English: Metadiscourse in slogans and headlines. Journal of Pragmatics, 33, 8.

[7] Leech, G. N. \& M. Short. (1981). Style in Fiction: A Linguistic Introduction to English Fictional Prose. London: Longman.

[8] Miller, G. (1980). On being persuaded: some basic distinctions. In G. Miller and M. Roloff, Persuasion: New Directions in Theory and Research. Beverly Hills: Sage.

[9] Ransom, E.N. (1997). Definiteness, animacy, and NP ordering. Proceedings of the Third Annual Meeting of the Berkeley Linguistics Society Berkeley.

[10] Sinclair, J. M. (1988). Mirror for a text. Journal of English and Foreign Languages 1.

[11] Tannen, D. (1989). Oh talking voice that is so sweet: Constructing dialogue in conversation// In Talking Voices: Repetition, Dialogue, and Imagery in Conversational Discourse. Cambridge: Cambridge University Press, 93-133.

[12] Tannen, D.(1993). What's in a frame? Surface evidence for underlying expectations. In Tannen, D (ed.) Frame in Discourse. New York: Oxford University Press, 15-56.

[13] Tatjra, L. (2001). Proverbs in Zimbabwean advertisements. Journal of Folklore Research, 38, 3, 229-241.

[14] Thompson, G. (1994). Reporting: Collins Cobuild English Guides 5. London: HarperCollins Publishers.

[15] Thompson, G. (1996). Voices in the text: Discourse perspectives on language reports. Applied Linguistics, 17, 4, $501-526$.

[16] Verstergaard, T \& K. Schroder. (1985). The Language of Advertising. Oxford: Basil Blackwell Ltd.

[17] Voloshinov, V. N. (1973).Marxism and the Philosophy of Language. (trans. Matejka, L. \& I. R. Titunik). New York: Seminar Press

Jianwu Peng was born in Shandong, China in 1964. He received his $\mathrm{Ph}$. D degree in linguistics from Fudan University, China in 2003.

He is currently a professor in the School of Foreign Languages, Shandong University of Science and Technology, Qingdao, China. Her research interests include sociolinguistics, pragmatics and discourse analysis. 